BMC

Genomics

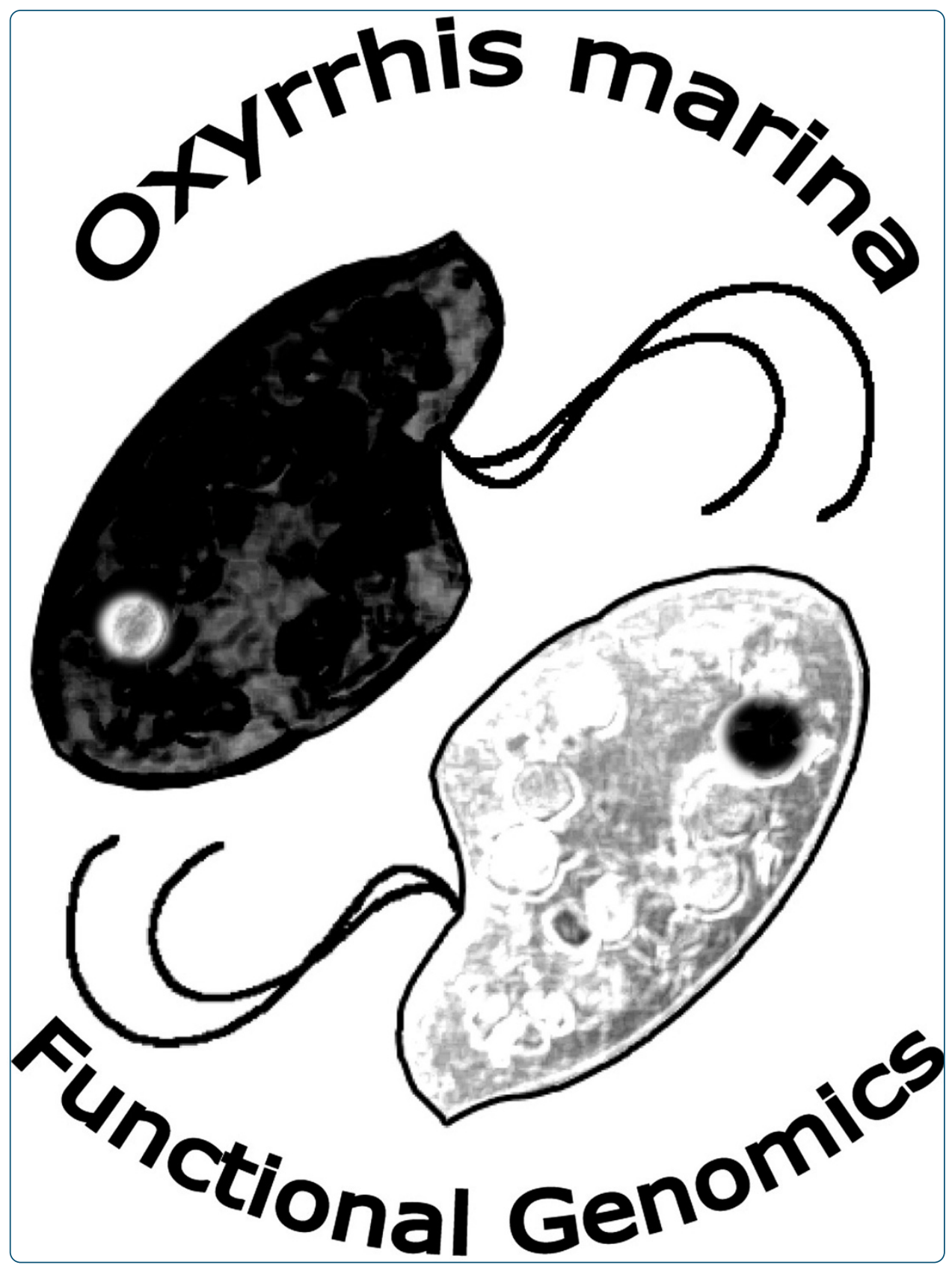

Analysis of EST data of the marine protist Oxyrrhis marina, an emerging model for alveolate biology and evolution

Lee et al.

C Biomed Central 


\title{
Analysis of EST data of the marine protist Oxyrrhis marina, an emerging model for alveolate biology and evolution
}

Renny Lee ${ }^{2}$, Hugo Lai ${ }^{2}$, Shehre Banoo Malik ${ }^{1,2}$, Juan F Saldarriaga ${ }^{3}$, Patrick J Keeling ${ }^{1,3}$ and Claudio H Slamovits ${ }^{1,2^{*}}$

\begin{abstract}
Background: The alveolates include a large number of important lineages of protists and algae, among which are three major eukaryotic groups: ciliates, apicomplexans and dinoflagellates. Collectively alveolates are present in virtually every environment and include a vast diversity of cell shapes, molecular and cellular features and feeding modes including lifestyles such as phototrophy, phagotrophy/predation and intracellular parasitism, in addition to a variety of symbiotic associations. Oxyrrhis marina is a well-known model for heterotrophic protist biology, and is now emerging as a useful organism to explore the many changes that occurred during the origin and diversification of dinoflagellates by virtue of its phylogenetic position at the base of the dinoflagellate tree.

Results: We have generated and analysed expressed sequence tag (EST) sequences from the alveolate Oxyrrhis marina in order to shed light on the evolution of a number of dinoflagellate characteristics, especially regarding the emergence of highly unusual genomic features. We found that $O$. marina harbours extensive gene redundancy, indicating high rates of gene duplication and transcription from multiple genomic loci. In addition, we observed a correlation between expression level and copy number in several genes, suggesting that copy number may contribute to determining transcript levels for some genes. Finally, we analyze the genes and predicted products of the recently discovered Dinoflagellate Viral Nuclear Protein, and several cases of horizontally acquired genes.
\end{abstract}

Conclusion: The dataset presented here has proven very valuable for studying this important group of protists. Our analysis indicates that gene redundancy is a pervasive feature of dinoflagellate genomes, thus the mechanisms involved in its generation must have arisen early in the evolution of the group.

Keywords: Dinoflagellates, Alveolates, Chromatin, Genome, Oxyrrhis

\section{Background}

The dinoflagellate Oxyrrhis marina is emerging as a popular model to study many aspects of heterotrophic protist biology including ecophysiology, behaviour, distribution and dispersal, swimming, motility as well as various aspects of cellular and nuclear biology [1]. Crucially, O. marina is well suited to explore the origins and the unusual characteristics of two important groups of protists, dinoflagellates and apicomplexans. In this regard, Oxyrrhis represents an early branch within the

\footnotetext{
*Correspondence: cslamo@dal.ca

${ }^{1}$ Canadian Institute for Advanced Research, Program in Integrated Microbial Biodiversity, Alberta, Canada

2Department of Biochemistry and Molecular Biology, Dalhousie University, B3H4R2 Halifax, NS, Canada

Full list of author information is available at the end of the article
}

dinoflagellate lineage. Its phylogenetic position has now been securely established as radiating close to the separation between apicomplexans and 'crown' dinoflagellates but after the oyster parasite Perkinsus marinus [2,3]. The status of Oxyrrhis as a dinoflagellate is not unanimous among protistologists $[4,5]$ but the basis for including it in the group, albeit as a divergent early representative are sound [5]. Regardless the preferred taxonomic treatment, Oxyrrhis offers a unique perspective to understand the evolution of these fascinating protists.

Dinoflagellates are known for their highly divergent features, such as expansive genomes, an unusual karyokinetic process and a very atypical chromatin structure, unique among eukaryotes [6-10]. Apicomplexans, on the other hand, exhibit some contrasting features such as a highly developed specialization for intracellular parasitism.

\section{Biomed Central}


Both groups have unusual organellar genomes, characterized by gene loss or transfer to the nucleus and unusual genomic architecture. Compared to many heterotrophs, $O$. marina is a robust organism that is easy to maintain in the laboratory; it grows fast and has flexible nutritional requirements [11,12]. These advantages explain in part why $O$. marina is a fashionable model organism, but lack of molecular data has been a severe limitation to the scope of questions that can be addressed with this species.

Over the last few years, we have carried out several studies using a dataset of expressed sequence tags (EST) from strain CCMP1788 of O. marina, which was used to addressed several specific questions on plastid evolution, lateral gene transfer, the structure of the mitochondrial genome and others [3,13-15]. Specifically, this dataset has revealed that at least eight genes are likely to have been inherited from a plastid-bearing ancestor while some of them showed strong signal of being related to genes from peridinin-containing dinoflagellates and apicomplexans [13], supporting the idea that the apicoplast and the photosynthetic plastid of dinoflagellates share an origin [13,16-18]. It has also revealed well-supported examples of horizontal gene transfer (HGT) [14,15], one of which involved the acquisition of rhodopsin proteins, which may have important functional implications [14]. Finally, EST data allowed a comprehensive characterization of the mitochondrial genome of O. marina, providing valuable insight into the complicated scenario of the evolution of these organelles in alveolates $[3,19,20]$. These examples highlight the value of the data generated by the O. marina EST project. More recently, Lowe et al. published a transcriptomic analysis of $O$. marina isolate 44-PLY01 (Plymouth Harbour, UK) based on 454 pyrosequencing, which constitutes the first attempt to use massively parallel DNA sequencing on this species [21]. Here we report the analysis of the full EST dataset, which is now available in its entirety in public databases, and give a general overview of the nature of the genes encoded in the O. marina genome, with particular discussion on the evolution of the nuclear genome and chromatin architecture.

\section{Methods}

\section{Strain, cultivation and EST library construction}

Oxyrrhis marina strain CCMP 1788 was cultivated in Droop's Ox-7 medium at the Bigelow Laboratory for Ocean Sciences (formerly CCMP). $20 \mathrm{~L}$ of culture was harvested in a continuous-flow centrifuge and stored in Trizol reagent (Invitrogen, Carlsbad, CA). Total RNA was prepared in $20 \mathrm{ml}$ batches according to the manufacturer's directions, resulting in $2 \mu \mathrm{g}$ of total RNA. A directional cDNA library from polyadenylated RNA was constructed in pBluescript II SK using EcoR1 and XhoI sites (Amplicon Express, Pullman, WA, USA), and shown to contain $5.3 \times 10^{5}$ cfu. 23,702 clones were picked and $5^{\prime}$-end sequenced using Sanger capillary sequencers (National Research Council, Halifax, NS, Canada). Quality control and vector trimming resulting in 18,012 EST sequences (deposited into GenBank EST database with accession numbers EG729650-EG747671) that assembled into 9,876 unique clusters using tbESTdb [22]. The clustering method implemented in tbESTdb is based on the phred/phrap algorithms [23] and ensures high discriminatory power to identify closely related paralogues and distinct gene copies [22]. The clusters were further examined manually using Geneious Pro versions 5 and 6 (Biomatters, Auckland, New Zealand) to assess quality. Sequences shorter than 200 bases were discarded because we observed a large proportion of low-quality and low-complexity, resulting in a filtered dataset of 8,141 sequences.

\section{Annotation and functional classification}

Sequences in the final dataset were searched against the NCBI non-redundant (nr) protein database using BLASTN and BLASTX to identify and annotate rRNA genes and protein coding genes, respectively. BLASTX was run two times, both with the default parameters except the cut-off E-value, which was set to $\leq 1 \mathrm{e}^{-10}$ and $\leq 1 \mathrm{e}^{-5}$ for each of the two BLASTX sessions. For clusters not yielding a hit in the first search $\left(\leq 1 \mathrm{e}^{-10}\right)$, we examined their hits in the second search set $\left(\leq 1 \mathrm{e}^{-5}\right)$ individually to distinguish spurious and useful matches. BLAST searches were done using Koriblast 3.0 (Korilog SARL, Questembert, France). The top match for each sequence was kept and the taxonomic affinity recorded for each entry. High-level taxonomic assignment was done manually. Assignment of functional categories and gene ontology to the top BLASTX hits was done with Blast2go [24]. Various sequence analyses and manipulations involving sequence alignments, conceptual translation, protein sequence examinations and calculations (e.g. molecular weight, isoelectric point) were carried out with Geneious v5.6 and v6. In addition, clusters with no hits to known proteins were searched for Pfam domains with Blast2Go (Additional file 1: Table S1).

\section{Identification of meiotic components}

Conserved proteins identified in lists of DNA repair and recombination proteins from the genome projects of Homo sapiens [25,26], Saccharomyces cerevisiae (http://db.yeastgenome.org), Trypanosoma brucei and T. cruzi [27,28], Trichomonas vaginalis [29] and refs. [30-33] were used to search a local database of inferred proteins from the genome sequences of Cryptosporidium parvum, Toxoplasma gondii (the smallest and largest sequenced apicomplexan genomes, respectively) and the oyster parasite Perkinsus marinus by batch BLASTP with an e-value cutoff of $1 \mathrm{e}^{-1}$. Similarly, C. parvum, $H$. sapiens and $S$. cerevisiae protein homologs were used to query the apicomplexan Ascogregarina taiwanensis genome survey 
sequence [34] by batch tBLASTn with an e-value cutoff of $1 \mathrm{e}^{-1}$. C. parvum, T. gondii, P. marinus, $H$. sapiens or $S$. cerevisiae inferred proteins were used to search the O. marina ESTs by tBLASTn with an e-value cutoff of $1 \mathrm{e}^{-1}$, and the identity of the best sequence hit(s) in O. marina verified by BLASTx against GenBank's non-redundant database. Phylogenetic analyses of individual candidate proteins were conducted with PhyML (http://www.atgc-montpellier. fr/phyml/) [35] using the amino acid conceptual translations aligned with MAFFT [36]. The maximum likelihood trees were built using the LG substitution model with invariant sites and $8 \gamma$-distributed substitution rate categories. Node support was assessed with 1,000 bootstrapping replicates.

\section{Real-time PCR estimation of relative expression}

RNA from O. marina cultures was extracted and purified with Aurum Total RNA mini kit (Bio-Rad, Hercules, CA) and cDNA was produced using Superscript III reverse transcriptase (Invitrogen, Carlsbad, CA). cDNA was quantified with a Qubit 2.0 fluorometer (Life Technologies, Carlsbad, CA). Sets of primers were designed for O. marina TVP1, Actin, Tubulin and Proteorhodopsin genes using the program PrimerSelect (DNASTAR, Inc., Madison, WI, USA) with its default parameters for real-time PCR. Tests for promiscuous binding were done using Blastn. Primers were ordered from Integrated DNA Technologies Inc., (Coralville, IA, USA). A full list of primer sequences and characteristics can be found in Additional file 1: Table S2. Real-time PCR was performed with a CFX96 instrument (Bio-Rad) and iQ SYBR Green Supermix (Bio-Rad). Expression level was expressed in relative units by entering the $\mathrm{Ct}$ value into the standard curves prepared for each gene as described [37].

\section{Results and discussion}

\section{ESTs and assembled clusters}

Although now superseded by ultra-high throughput sequencing methods, cloning based cDNA library construction followed by directional Sanger sequencing remains a powerful way to analyse the gene complement of an organism because high quality, long read sequence offers the possibility to obtain full-length sequences of individual clones. We used this method to conduct a genome-wide survey of expressed genes in O. marina, aiming to shed light on some aspects of alveolate biology and evolution.

A total of 23,702 clones were sequenced from the 5' end, of which 18,012 remained after quality filtering and vector trimming. The ESTs were assembled using the tbESTdb pipeline [22], resulting in 9,876 unique clusters (unigenes, [38]). Visual inspection of the clusters revealed that a large number of the short clusters were low complexity repeats, thus we decided to discard all sequences shorter than 200 bases in order to prioritize the quality of the data, resulting in a final set of 8,141 clusters. The size distribution of ESTs is bimodal, with a peak between 650 and 750 bases and another between 50 and 150 bases (not shown), suggesting that substantial of degradation in the RNA sample took place.

\section{Taxonomic distribution of blast hits}

We used NCBI Blast to assign putative functional identity by similarity with the aid of Koriblast and Blast2go. Searching with the Blastn algorithm against NCBI's non-redundant nucleotide database (nr) identified 6 clusters matching rRNA genes: four clusters correspond to pieces of the fragmented mitochondrial rRNA genes, which have already been analysed [3], one to nuclear small subunit RNA (SSU), and two to the nuclear large subunit RNA gene (LSU) (Table 1). Both SSU and LSU transcripts are very abundant compared to most RNA species in the sample, with 88 and 172 ESTs, respectively.

Having excluded rRNA genes and sequences shorter than 200 bases, we conducted Blastx searches against the $\mathrm{nr}$ database with a cutoff $E$ value set to $e \leq 1 x-05$. The search produced 4,515 sequences with matches. Examining alignments with lower Blast scores, we noticed that many were false positive results due to spurious similarity between repeats in the clusters and low-complexity protein sequences in the database, so we set a stricter cutoff at $E \leq 1 x-10$, resulting in 4,222 hits. Of these, 633 corresponded to bacteria, 30 to viruses and 14 were similar to members of Archaea (Figure 1). The remaining 3,545 positive hits were similar to eukaryotic sequences. Figure 1 shows the distribution of the eukaryotic hits by taxonomic groups: alveolates make up about one third of the total (1,385 clusters), then opisthokonts (metazoan and fungi) with 1,116 and Archaeplastida (plants, green and red algae) with 561. The remaining fraction was composed of Stramenopiles (e.g. diatoms, brown algae, oomycetes), excavates (e.g. euglenids, kinetoplastids, parabasalia), haptophytes, cryptophytes and cercozoans. Within

\begin{tabular}{lcc}
$\begin{array}{l}\text { Table } 1 \text { Identity of the } \\
\text { O. marina }\end{array}$ EST clusters encoding \\
mitochondrial transcripts and nuclear ribosomal RNA genes \\
\hline Gene & Clusters & Total ESTs \\
\hline cox1 & 1 & 339 \\
cob-cox3 fusion & 1 & 130 \\
LSU-E & 1 & 14 \\
LSU-E & 1 & 53 \\
LSU-rna10 & 1 & 18 \\
LSU-G & 1 & 1 \\
Nuclear SSU & 1 & 88 \\
Nuclear LSU & 2 & 172 \\
\hline
\end{tabular}

For each type, the number of distinct clusters and the number of ESTs per clusters is indicated. 


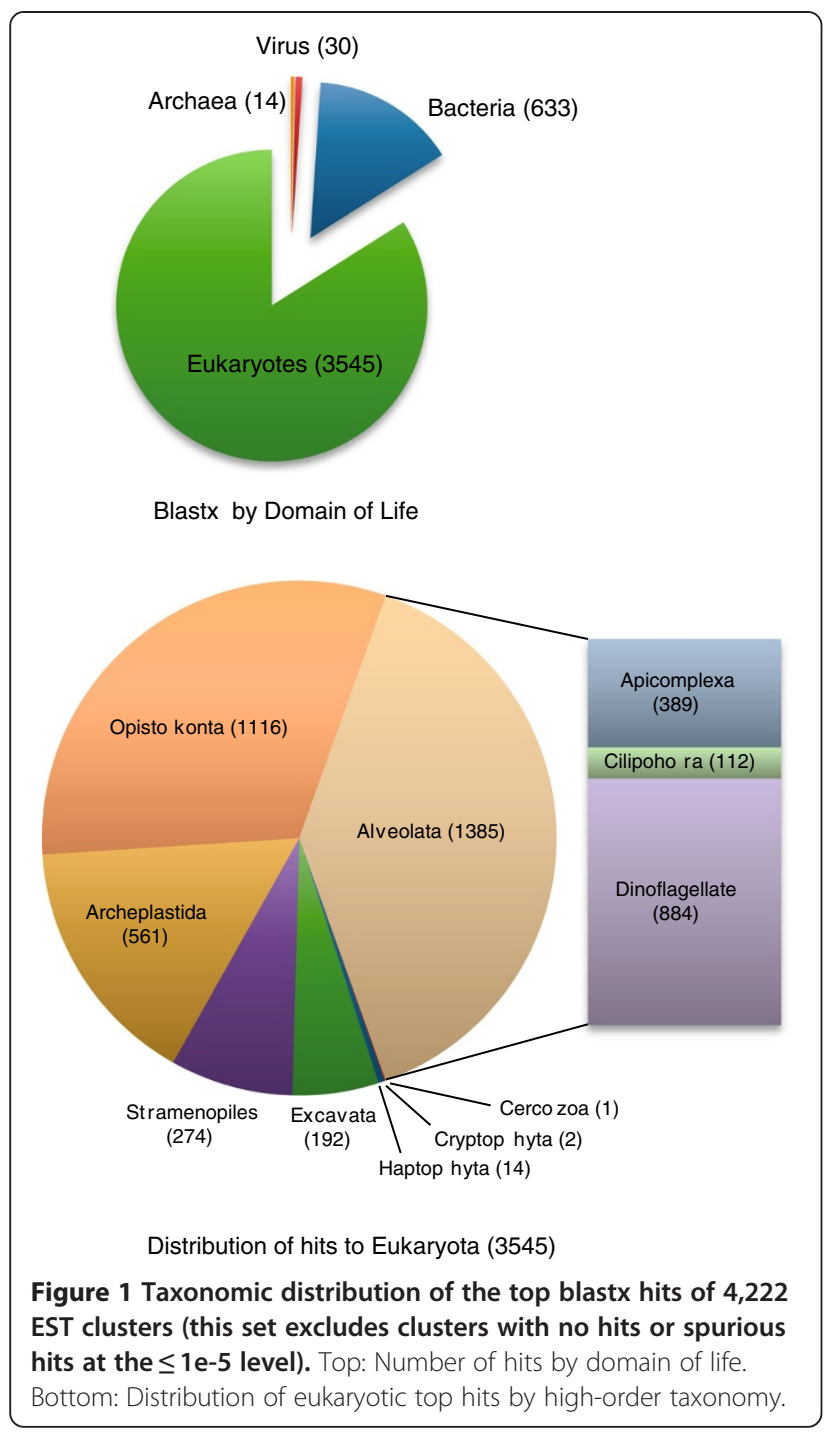

alveolates, most top hits were from dinoflagellates (884) followed by apicomplexans (389) and ciliates (112). Not surprisingly, the largest part of the dinoflagellate hits comes from a single species, the oyster parasite Perkinsus marinus with (the genus Perkinsus is often classified in its own Phylum Perkinsozoa [4,39]). P. marinus is the only member of the dinoflagellate lineage with a genome project at an advanced stage (at the time of writing a presumably complete set of genes have been annotated and deposited in Genbank, but the analysis has not yet been published). (Note added during revision: a draft genome project of Symbiodinium sp. was published recently [40]). Dinoflagellates are still comparatively underrepresented in databases, especially in the protein databases as most sequences produced so far have been deposited as ESTs. Hits to apicomplexan species are not as conspicuous as one would expect considering that Apicomplexa is the sister taxon to dinoflagellates and there are about ten complete genomes from apicomplexan parasites in public databases. This could be a consequence of the high degree of specialization that characterizes the phylum Apicomplexa, typically exhibiting high divergence of protein sequences and heavy gene loss. Sequences with top Blast similarity to animals and fungi collectively (i.e. Opisthokonta) represent a similar fraction as alveolates (Figure 1). This set of genes probably represents a core of well-conserved and ubiquitous eukaryotic genes of very deep ancestry, a class of genes that usually exhibits little correlation between Blast similarity and phylogenetic affinity (and also likely reflects the large number of animal and fungal genomes that are available). The remaining one-third of Blast hits correspond to plants, green and red algae, stramenopiles and excavates (Figure 1). In part, these assignments are probably due to similar factors as those from animals and fungi, but could also include sequences with different evolutionary histories for at least two reasons. First, all alveolates, or at least the clade conformed by apicomplexans and dinoflagellates [17] descend from plastid-harbouring ancestors and as such, their nuclei contain many genes derived from that ancient photosynthetic endosymbiont that may be contributing to the hits to archaeplastids and stramenopiles. Eight genes likely to be inherited from a plastid from this sample have been reported in a previous paper [13]. On the other hand, however, if these genes were really derived from the endosymbiont, they might be expected to be found in ciliate genomes as well, but the evidence for this is still controversial [41-43]. Second, O. marina is a voracious predator and its diverse menu includes mainly green and red algae as well as many stramenopiles and haptophytes. Continuous repeated exposure to prey could have resulted in a number of genes being transferred and integrated into the nuclear genome [44].

Overall, roughly half of the sequences had no significant matches to known proteins deposited in the $\mathrm{nr}$ database. Clearly, the fraction of sequences with no Blastx matches in GenPep depends on the abundance of sequences from related organisms in the database and on how atypical is the organism in its gene content and degree of sequence divergence. As more genomes in a group of related organisms are sequenced and annotated, the first factor becomes less relevant and the fraction of unmatched sequences decreases. Figure 2 shows the distribution of top Blast hits when we searched NCBI's "est-others" database using the $O$. marina ESTs that returned no significant hits in the previous search. The preponderance of plants and animals simply reflects the largely biased composition of the database, whereas the next fraction in abundance corresponds to dinoflagellates in spite of the comparatively low representation of these protists in the database. The fraction of unmatched Blast sequences in $O$. marina at the $\mathrm{E} \leq 1 \mathrm{xe}-10$ threshold is $47 \%$, which is in line with other estimates: $53 \%$ 


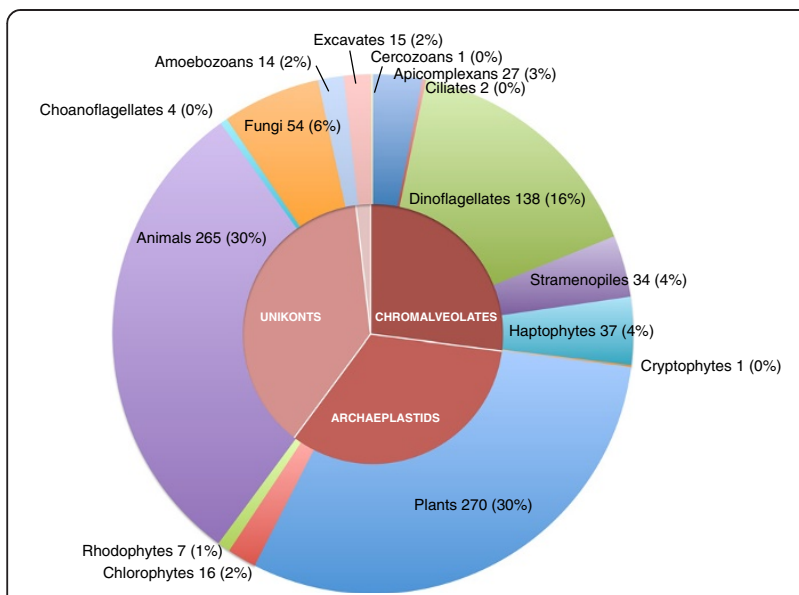

Figure 2 EST clusters of $O$. marina with no hits to NCBI's non-redundant protein database were searched against the NCBI's 'est-others' database using tblastx (compares translated amino acid sequences using nucleotide queries and database). The pie chart shows the taxonomic distribution of the top hits $(\leq 1 \mathrm{e}-5)$. Number of hits and percentage are shown. The central circle indicates major eukaryotic groupings of the portions in the external circle.

for Alexandrium catenella [45], 71\% for Karenia brevis [46], 63\% for a combined set from Amoebophrya sp. and Karlodinium veneficum [47] and $72 \%$ for A. minutum [48]. Variation is due to a mix of factors, including nonstandardized criteria to determine cutoff, potential biases from library construction and sample size and increasingly better representation of dinoflagellate genes in the databases. We also compared our EST dataset to the transcriptomic data generated by 454 pyrosequencing by Lowe et al. [21]. Even though the number of clusters (contigs) in both studies is roughly similar (ca. 8,000), the overlap in sequence identity was very low. Only $23 \%$ of our EST dataset (sequences 200 bp or longer) had one or more blastn hits $(E \leq 1 x e-5)$ among the 7,398 sequences in the 454 dataset. While the two samples come from closely related organisms, we also used tblastx to compare at the predicted amino acid level in case divergence at the nucleotide level was too high. This time the overlap increased slightly to $29 \%$.

\section{Bacterial sequences}

The ESTs from O. marina contains 633 sequences for which the top Blast hit is bacterial. Many of those probably reflect sampling artifacts that result in misleading top Blast hits and others might represent genes with an evolutionary origin different from the $O$. marina nucleus (i.e. horizontal and endosymbiotic gene transfer). We also detected a sizeable fraction with very high similarity to alpha-proteobacteria of the order Rhodobacterales, mainly from the genus Oceanicaulis. We examined these sequences closely and they do not appear to be derived from genuine, polyadenylated mRNA. First, they are extremely similar, often identical to the annotated genome of the bacterium $O$. alexandrii. Second, the orientation of the coding sequence appears to be equally distributed between forward and reverse, and third, some individual ESTs even contain portions of genes that are adjacent in the $O$. alexandrii genome. We conclude that these sequences are most likely derived from a contamination with bacterial DNA during the library construction. $O$. alexandrii has been isolated from cultures of the dinoflagellate Alexandrium and several Rhodobacterales are known to coexist with dinoflagellates, even as symbiotic partners [49-53]. Likely, symbiotic bacteria that resist methods to generate axenic cultures accompany the $O$. marina culture. We observed that $O$. marina cells that had been grown with antibiotics still contain tightly associated bacteria (Figure 3). Overall, the O. alexandrii Blast matches accounted for 82 of the genes with top hits to bacteria (13\%, not shown), leaving a sizable number of genes, many of which could still come from symbionts but others may have resulted from HGT. Unfortunately there are no available data to confirm this possibility, since our ESTs typically do not include the spliced leader sequence characteristic of the $5^{\prime}$ end of dinoflagellate genomes $[46,54]$.

\section{Extensive gene redundancy}

In many cases, ESTs apparently encoding the same gene were assembled as separate clusters of highly similar sequence (albeit below the strict threshold for assembly). Close examination of the raw files revealed that this is not due to sequencing errors or low quality, but to the presence of genuinely distinct copies of many genes, in some cases over 40. Multi-copy genes have been described previously in dinoflagellates, often as tandems of as many as 5,000 adjacent copies $[55,56]$ and recently, hints for disperse arrangements affecting many genes have been reported by sequencing $[21,57]$ and fluorescent in situ hybridization [58] techniques. The pyrosequencingbased transcriptomic study by Lowe et al. detected a number of redundant genes, including tandem arrangements [21], but we did not find extensive overlap in multicopy genes between both studies: only three genes (hsp70, hsp90 and S-adenosyl-methionine synthetase) in our list from Table 2 were also found to be redundant in the Lowe et al. analysis.

Accumulating evidence suggests that prevalence of multicopy genes in dinoflagellates is more common than in other organisms [57,59-62], but a thorough assessment of the prevalence of gene redundancy in one organism is lacking. In our sample, among the sequences with positive Blast hits, 422 were represented by two or more distinct clusters, 64 sequences by 4 or more clusters and 11 genes were represented by 10 to 42 clusters (Table 2). Since 


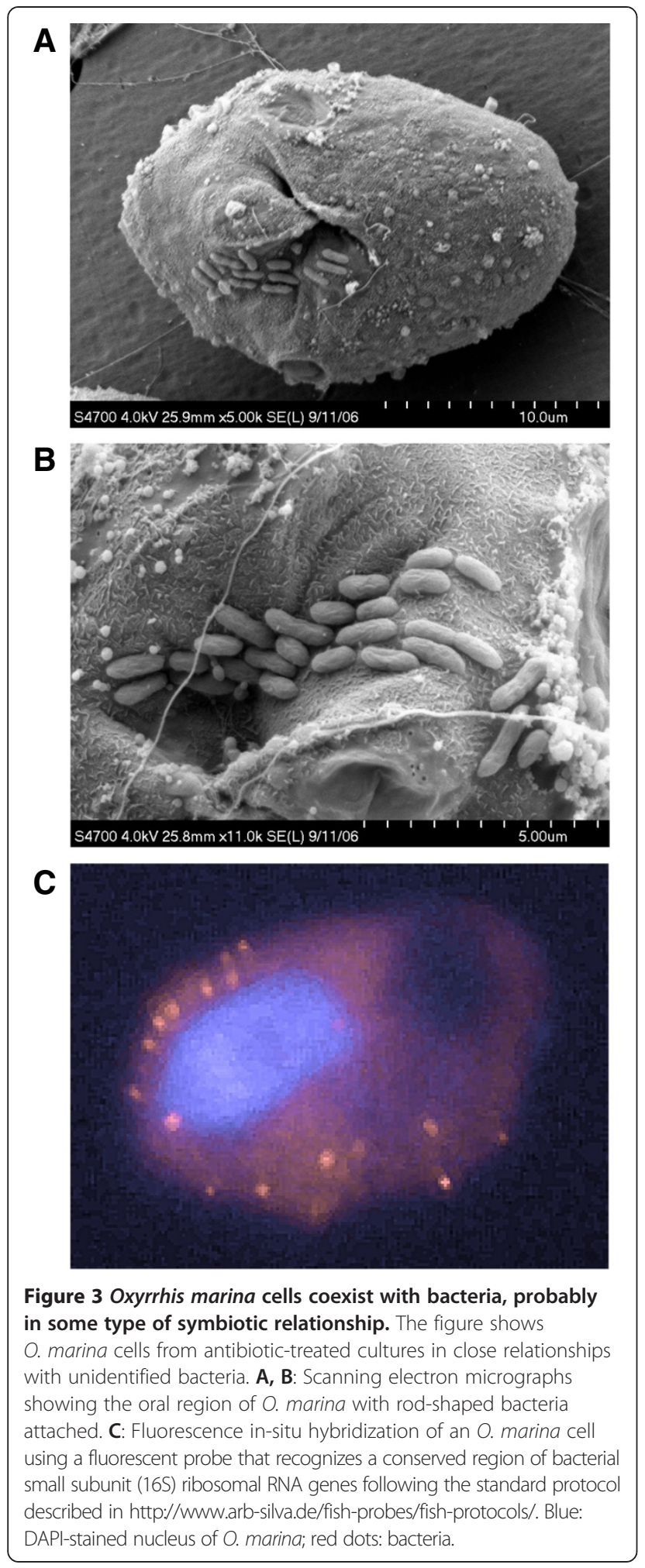

ESTs are clustered only if they are highly similar, different clusters with the same blast hits probably represent different genomic loci, but the opposite may or may not be true: genes present in multiple but identical copies cannot be recognized by this approach, since all ESTs originating from all the units will cluster in a single contig. Tandem arrangements of identical copies have been described in dinoflagellates, therefore they may occur in O. marina as well. In fact, Lowe et al. found evidence of tandemly arranged genes encoding Beta and Alpha tubulin, EF-2, Rhodopsin and HSP90 with intergenic spacers ranging between 200 and 400 bp [21].

In contrast to the protein-coding genes, we found that expressed nuclear rRNA genes are highly homogeneous: all 88 ESTs from small subunit cluster to a single contig, whereas the 172 ESTs from the large subunit cluster to 2 contigs (Table 1 ). Long operons of identical or nearly identical units of rRNA genes are very common in eukaryotic genomes, and the high level of similarity among the copies has been attributed to gene conversion and other mechanisms that result in concerted evolution [63]. The sequence heterogeneity observed in many protein-coding genes may reflect particular genomic conditions that prevent them from achieving or maintaining homogeneity. However, concerted evolution depends on genomic and biological factors such as the spatial distribution of the repeated genes (i.e. whether tandemly arranged or scattered) and the frequency of somatic and meiotic recombination, all features almost virtually unknown in dinoflagellates.

\section{Levels of gene expression and gene variants}

We observed large variations in the number of ESTs per cluster (Tables 2 and 3). As reported previously, the most abundant corresponded to mitochondrial coxI, while mitochondrial cob-coxIII fusion was also among the top with 130 ESTs ([3], Table 1). Of the nucleus-encoded genes, proteorhodopsin was the most highly expressed ([14]). Aside for housekeeping genes typically highly expressed in eukaryotic cells (hsp90, actin, tubulins, EFL, ribosomal proteins), the list of most abundant ESTs is populated almost exclusively by metabolic proteins, suggesting that at the time of harvesting the cells were in active metabolic state (Additional file 2: Figure S1). Notable among the metabolic genes are alcohol dehydrogenase and the glyoxylate cycle enzyme isocitrate lyase, suggesting active utilization of $2 \mathrm{C}$ molecules such as ethanol or acetate as carbon sources. Interestingly, another highly expressed gene is Gpr1/Fun34/YaaH, whose product is essential for acetate permease activity in Aspergillus and its mutation trigger hypersensitivity to acetic acid in yeast $[64,65]$. When grown with prey food, O. marina cells behave voraciously and one individual can easily ingest three or four prey cells, which in the case of the green alga Dunaliella tertiolecta, are about half the size of an O. marina cell. Consistently, we observed evidence of intense protein degradation activity in the form of high expression levels of cysteine protease 1 (132 ESTs, Table 3). 
Table 2 Identity inferred as top BlastX hits of the 0 . marina genes with largest numbers of distinct clusters

\begin{tabular}{|c|c|c|c|c|}
\hline Hit accession & Clusters & Total Ests & Definition & Species \\
\hline $\mathrm{AAO} 14677$ & 42 & 240 & Proteorhodopsin & Pyrocystis lunula \\
\hline ABV72550 & 25 & 87 & DVNP & Heterocapsa triquetra \\
\hline ZP_07751542 & 23 & 152 & GPR1/FUN34/yaaH family protein & Mucilaginibacter paludis \\
\hline BAE79387 & 13 & 41 & Actin & Symbiodinium sp. CS-156 \\
\hline ABV22332 & 12 & 132 & Cysteine protease 1 & Noctiluca scintillans \\
\hline XP_002506839 & 12 & 61 & Acetate-coa ligase & Micromonas sp. RCC299 \\
\hline XP_002500277 & 11 & 27 & Acetyltransferase-like/FAD linked oxidase & Micromonas sp. RCC299 \\
\hline AAM02973 & 10 & 90 & Heat shock protein 70 & Crypthecodinium cohnii \\
\hline XP_002775922 & 10 & 27 & Succinate dehydrogenase, putative & Perkinsus marinus \\
\hline XP_002780969 & 10 & 25 & Heterogeneous nuclear ribonucleoprotein, putative & Perkinsus marinus \\
\hline ACl12882 & 9 & 122 & NAD-dependent alcohol dehydrogenase & Euglena gracilis \\
\hline CBJ30560 & 8 & 20 & Glutathione S-transferase & Ectocarpus siliculosus \\
\hline XP_002786250 & 8 & 8 & 40 S ribosomal protein 59 , putative & Perkinsus marinus \\
\hline AAW79379 & 7 & 36 & Fumarate reductase & Heterocapsa triquetra \\
\hline XP_002787701 & 7 & 35 & 14-3-3 protein, putative & Perkinsus marinus \\
\hline ZP_06799564 & 7 & 8 & Hypothetical protein & Mycobacterium tuberculosis \\
\hline ABI14419 & 6 & 39 & Heat shock protein 90 & Karlodinium micrum \\
\hline AAV71134 & 6 & 23 & Cytosolic class II fructose bisphosphate aldolase & Heterocapsa triquetra \\
\hline ABF22754 & 6 & 16 & Mitochondrial cytochrome c oxidase subunit $2 \mathrm{~b}$ & Karlodinium micrum \\
\hline ACA60905 & 6 & 15 & Gag-pol polyprotein & Thalassiosira pseudonana \\
\hline ZP_07985860 & 6 & 12 & ATP-dependent DNA helicase & Streptomyces sp. \\
\hline YP_002500649 & 6 & 6 & Peptidase $C 14$, caspase catalytic subunit p20 & Methylobacterium nodulans \\
\hline XP_002765341 & 5 & 46 & S-adenosylmethionine synthetase, putative & Perkinsus marinus \\
\hline ABG56231 & 5 & 38 & Translation elongation factor-like protein & Karlodinium micrum \\
\hline XP_001763482 & 5 & 23 & Acetyl-CoA synthetase & Physcomitrella patens \\
\hline XP_002184734 & 5 & 22 & Predicted protein & Phaeodactylum tricornutum \\
\hline XP_002769616 & 5 & 21 & Conserved hypothetical protein & Perkinsus marinus \\
\hline NP_001068397 & 5 & 17 & Hypothetical protein & Oryza sativa \\
\hline AAG01128 & 5 & 17 & Hypothetical protein & Solanum lycopersicum \\
\hline
\end{tabular}

Three enzymes of the S-adenosyl-L-homocysteine metabolism are also highly expressed: adensyl homocysteine hydrolase, adenosyl methionine synthetase and adenosyl homocysteinase (Table 3), which participate in several metabolic pathways, mainly the synthesis of adenosine, methionine and cysteine.

At face value, these numbers suggest that some genes are relatively highly expressed; however to test whether this has any correspondence to mRNA levels in the cell, we conducted real-time quantitative PCR (qPCR) on a sample of genes. Specifically, mRNA levels of four genes, proteorhodopsin (PR), TVP1, alpha tubulin (Atub) and actin were quantified from $O$. marina culture grown in similar conditions as the original culture. In coincidence with the estimation from EST abundance, PR and TVP1 were first and second in the qPCR estimation with 50,000 and 18,100 relative units, respectively (not shown). For
Atub and actin 4,200 and 1,000 relative units were estimated, respectively. Albeit preliminarily, this test shows correspondence between the number of ESTs for a given gene and the qPCR estimation of gene expression, but conclusions based on this evidence must be taken with caution until a more rigorous experiment is conducted. There are many factors, both biological and technical that could explain differences between EST abundance and qPCR estimation $[21,66]$. In this case, the multicopy structure of the genome may constitute an additional complication since qPCR primers pick only a restricted sample of the mRNAs encoding a particular type of protein, resulting in potentially large sampling errors.

Moreover, it is now emerging that in dinoflagellates gene expression is largely modulated posttranscriptionally [61,62,67-69]. If so, transcriptional regulation may have little relationship to the protein levels, and increasing 
Table 3 Identity inferred as top BlastX hits of the O. marina genes with largest numbers of ESTs

\begin{tabular}{|c|c|c|c|c|}
\hline Hit accession & Clusters & Ests & Definition & Species \\
\hline $\mathrm{AAO} 14677$ & 42 & 240 & Proteorhodopsin & Pyrocystis lunula \\
\hline ZP_07751542 & 23 & 152 & GPR1/FUN34/yaaH family protein & Mucilaginibacter paludis \\
\hline ABV22332 & 12 & 132 & Cysteine protease 1 & Noctiluca scintillans \\
\hline ACl12882 & 9 & 122 & NAD-dependent alcohol dehydrogenase & Euglena gracilis \\
\hline AAM02973 & 10 & 90 & Heat shock protein 70 & Crypthecodinium cohnii \\
\hline ABV72550 & 25 & 87 & DVNP & Heterocapsa triquetra \\
\hline ZP_01726360 & 2 & 63 & Aldehyde dehydrogenase & Cyanothece sp. \\
\hline XP_002950429 & 3 & 62 & S-Adenosyl homocysteine hydrolase & Volvox carteri \\
\hline XP_002506839 & 12 & 61 & Acetate-coa ligase & Micromonas sp. \\
\hline XP_002765341 & 5 & 46 & S-adenosylmethionine synthetase, putative & Perkinsus marinus \\
\hline XP_002784353 & 3 & 43 & $\mathrm{H}+$-translocating inorganic pyrophosphatase TVP1, & Perkinsus marinus \\
\hline YP_130418 & 3 & 42 & L-lactate permease & Photobacterium profundum \\
\hline BAE79387 & 13 & 41 & Actin & Symbiodinium sp. \\
\hline ABI14419 & 6 & 39 & Heat shock protein 90 & Karlodinium micrum \\
\hline ABG56231 & 5 & 38 & Translation elongation factor-like protein & Karlodinium micrum \\
\hline AAW79379 & 7 & 36 & Fumarate reductase & Heterocapsa triquetra \\
\hline XP_002787701 & 7 & 35 & 14-3-3 protein, putative & Perkinsus marinus \\
\hline XP_002766754 & 2 & 30 & $40 S$ ribosomal protein S11, putative & Perkinsus marinus \\
\hline XP_002500277 & 11 & 27 & Acetyltransferase-like/FAD linked oxidase & Micromonas sp. RCC299 \\
\hline XP_002775922 & 10 & 27 & Succinate dehydrogenase, putative & Perkinsus marinus \\
\hline ABD46571 & 4 & 27 & Alcohol dehydrogenase-like protein & Euglena gracilis \\
\hline XP_002786429 & 4 & 27 & Osmotic growth protein, putative / Fumarate reductase & Perkinsus marinus \\
\hline XP_002904993 & 2 & 26 & Isocitrate lyase & Phytophthora infestans \\
\hline XP_002780969 & 10 & 25 & Heterogeneous nuclear ribonucleoprotein, putative & Perkinsus marinus \\
\hline ZP_06800645 & 3 & 25 & Heat shock protein & Mycobacterium tuberculosis \\
\hline XP_002773236 & 1 & 25 & Ribonucleotide reductase small subunit, putative & Perkinsus marinus \\
\hline ABV22229 & 3 & 24 & ATP/ADP translocator & Karlodinium micrum \\
\hline YP_638223 & 3 & 24 & Nucleotide-diphosphate-sugar epimerase/NmrA family protein & Mycobacterium sp. MCS \\
\hline AAV71134 & 6 & 23 & Cytosolic class II fructose bisphosphate aldolase & Heterocapsa triquetra \\
\hline XP_001763482 & 5 & 23 & Acetyl-CoA synthetase & Physcomitrella patens \\
\hline XP_001638515 & 3 & 23 & No hits & \\
\hline CBX99834 & 2 & 23 & Similar to cytochrome b2 & Leptosphaeria maculans \\
\hline XP_002786953 & 2 & 23 & Tubulin alpha chain, putative & Perkinsus marinus \\
\hline XP_002184734 & 5 & 22 & Predicted protein & Phaeodactylum tricornutum \\
\hline ABF61766 & 3 & 22 & Chloroplast 3-dehydroquinate synthase/O-methyltransferase & Heterocapsa triquetra \\
\hline XP_002788505 & 3 & 22 & Hypothetical protein & Perkinsus marinus \\
\hline ABU52986 & 2 & 22 & Beta-tubulin & Karenia brevis \\
\hline XP_002911883 & 9 & 21 & Hypothetical protein & Coprinopsis cinerea \\
\hline XP_002769616 & 5 & 21 & Conserved hypothetical protein & Perkinsus marinus \\
\hline XP_002780466 & 3 & 21 & 2-methylcitrate synthase, putative & Perkinsus marinus \\
\hline CBJ30560 & 8 & 20 & Glutathione S-transferase & Ectocarpus siliculosus \\
\hline XP_666127 & 3 & 20 & Ribosomal protein L5A & Cryptosporidium hominis \\
\hline AAN31463 & 1 & 20 & Glutamine synthetase & Phytophthora infestans \\
\hline
\end{tabular}


Table 3 Identity inferred as top BlastX hits of the O. marina genes with largest numbers of ESTs (Continued)

\begin{tabular}{lllll}
\hline ACJ13434 & 3 & 19 & Adenosylhomocysteinase & Amphidinium carterae \\
XP_002766763 & 2 & 19 & Protein TIS11, putative & Perkinsus marinus \\
XP_001612035 & 2 & 18 & Conserved hypothetical protein & Babesia bovis \\
NP_001068397 & 5 & 17 & Hypothetical protein & Oryza sativa \\
AAG01128 & 5 & 17 & Hypothetical protein & Solanum lycopersicum \\
AAX27763 & 4 & 17 & Hypothetical protein & Toxoplasma gondii \\
AB113175 & 2 & 17 & Asparaginyl endopeptidase & Emiliania huxleyi \\
XP_002776404 & 1 & 17 & Methylenetetrahydrofolate reductase, putative & Perkinsus marinus \\
ABI14188 & 1 & 17 & ADP-ribosylation factor & Pfiesteria piscicida \\
ABF22754 & 6 & 16 & Mitochondrial cytochrome c oxidase subunit 2b & Karlodinium micrum \\
XP_002765511 & 2 & 16 & 40S ribosomal protein S3a, putative & Perkinsus marinus \\
XP_002772672 & 2 & 16 & Vacuolar ATP synthase subunit b, putative & Perkinsus marinus \\
\hline
\end{tabular}

the number of functional transcriptional units could be an alternative way to maintain high levels of mRNA of certain genes. In our data, highly expressed genes tend to exhibit more distinct variants (Tables 2 and 3), raising the intriguing possibility that dinoflagellates modulate baseline expression levels by, at least in part, increasing the number of copies of the gene instead of (or in addition to) adjusting transcription levels.

\section{Functional categorization of the 0 . marina ESTs DNA repair and meiosis}

We identified 27 O. marina transcripts homologous to genes conserved in humans, yeast, and other protists that were functionally linked to the recognition and repair of damaged DNA in model animals or fungi $[25,26]$ (Additional file 1: Table S3). These include components of the excision repair machinery, DNA double-strand break repair by homologous recombination (HR), editing and processing nucleases (EPN), post-replication repair (PRR), chromatin structure (CS), the DNA damage checkpoint (DDC), DNA replication licensing (DRL), and DNA damage response (DDR). Excision repair protein homologs encoded by $O$. marina include (i) break excision repair (BER) poly (ADP-ribose) polymerase PARP2 that protects single-strand DNA interruptions, (ii) mismatch repair (MMR) protein Mlh1, a mutL homolog also required for meiotic crossovers, and for (iii) nucleotide excision repair (NER), replication factor $A$ (RFA1) that binds to sites of DNA damage, and the XPD/ERCC2 5'-3' helicase that helps unwind the pre-incision intermediate. Homologs of DNA polymerase catalytic subunits delta, epsilon and PCNA, employed in MMR and NER, were also identified in O. marina. Components of the HR machinery include the SbcD 3' exonuclease homolog Mre11, RecA recombinase homolog Rad51, Brca1, a sister chromatid cohesin subunit (Smc3), homologous condensin subunits Smc2 and Smc4, and meiosis-specific Hop2 and Spo11-2
(Additional file 2: Figure S1 and Additional file 3: Figure S2). Conserved homologs of a flap endonuclease (FEN1), the DNA damage response and checkpoint signaling machinery (Suc1, Rad17, Chk1, Chk2) and the DNA replication licensing complex (Mcm3, Mcm5 and Mcm7) are also encoded by $O$. marina. Components of the postreplication repair Rad6 pathway (Rad6A, $\operatorname{Rad6B)}$ are present. Proteins involved in chromatin structure such as BLM, RecQ helicases are also identified.

These findings indicate that $O$. marina encodes conserved components of several eukaryotic recombination and repair pathways, except for non-homologous end joining (NHEJ). Since the proteins encoded by these genes interact together with other conserved DNA repair proteins where studied in other eukaryotes, we expect that additional O. marina genomic or transcriptomic data will reveal homologous genes encoding other key DNA repair and recombination proteins, including additional members of the ERCC, XRCC and Rad52 epistasis groups, additional MutL and MutS homologs involved in mismatch repair, and more meiosis-specific homologs.

To date, a single report on sexual reproduction has been published for $O$. marina [70,71]. Based on observations of small cells presumed to be gametes, the paper claims that O. marina cells engage in sexual reproduction, but no data support the occurrence of meiotic division [72]. Moreover, even the ploidy status and most details about the life cycle of O. marina are poorly known $[58,72]$. Since O. marina encodes meiosis-specific Spo11-2 and Hop2 genes, we expect other "core meiotic genes" $[73,74]$ not yet detected might also be present. Since Spo11-2 and Mre11 genes are present, we expect to find Rad50, since Rad50 and Mre11 act together in other eukaryotes to remove Spo11 from DNA ends in meiosis and also process DNA ends during mitotic HR. Since Hop2 is present, meiosis-specific Mnd1 and Dmc1 homologs might also be encoded, since in other eukaryotes Hop2 and Mnd1 form a complex that interacts 
with Dmc1 in interhomolog strand exchange. Presence of these pieces of the conserved meiotic machinery indicates that meiosis is indeed part of the life cycle of O. marina, although probably in a very inconspicuous way. Possibly the conditions in which we generated the RNA (i.e. exponential growth) favours asexual reproduction, hence the paucity of meiosis-related genes in our sample. This also means that the life cycle must include diploid (or polyploidy) stages.

\section{Chromatin architecture and remodeling}

Dinoflagellates have long been known as 'rule breakers' because they present exceptions to many well-established rules of eukaryotic cell biology. For example, numerous lines of evidence suggest that typical nucleosomal organisation of the chromatin is absent in dinoflagellates, and what histones remain do not function in the same capacity as in other eukaryotes $[8,9]$. Instead, the chromatin appears to be rich in basic proteins but the way in which nuclear DNA and proteins interact is still unknown $[6,7,10,75,76]$. This raises the fundamental question of the involvement of chromatin organisation for transcriptional regulation in dinoflagellates. Gene regulation through chromatin remodeling is a ubiquitous eukaryotic feature that exhibits variations but the essential aspects are presumed to be present in all eukaryotes. Evidence that histone genes are present and indeed expressed in dinoflagellates is starting to emerge, suggesting that these proteins probably play some role in chromatin organisation [75,77]. Since chromatin organisation at the molecular level appears to be typical in Perkinsus, the most basal lineage of the dinoflagellate tree for which genomic data is available, the data from $O$. marina could provide valuable hints on the early stages of the transformations leading to the unusual nature of the dinoflagellate chromatin. We looked for evidence of histones and chromatin remodeling sequences in O. marina and found no clear histone homologues; neither the typical eukaryotic nor the histone-like proteins of bacterial origin that have been reported in Crypthecodinium [78]. We did find one sequence with high similarity $\left(\mathrm{E}<1 \times 10^{-48}\right)$ to a histone deacetylase of the AcuC/AphA family and another with similarity to Sir2, another conserved histone deacetylase of the Sirtuin family involved in epigenetic silencing. Even if we assume that histones should be present as suggested by recent findings on other species, failure to find transcripts in our sample is not surprising given that their evidence has remained elusive in several other studies and when found, histone transcripts binned among the lowly expressed genes. In animals and plants, replication-dependent histone transcripts are not polyadenylated, and in yeasts, the length of the polyA tail of histones varies with the stage of the cell cycle. Difficulty in detecting histone transcripts in dinoflagellates may also reflect the existence of similar mechanisms of transcriptional regulation involving short or absence of polyA tails. A recent study in the parasitic dinoflagellate Hematodinium sp. described a novel protein named DVNP (for Dinoflagellate Viral Nuclear Protein), which appears to be a main basic protein found in the chromatin [75]. In the study, micrococcal nuclease digestion of intact Hematodinium chromatin failed to yield the typical nucleosomal band pattern on an agarose gel, unlike $P$. marinus, which yield the $180 \mathrm{bp}$ ladder expected from partial nucleosomal DNA digestion [75]. The concomitant presence of these two features in Hematodinium and not in Perkinsus suggests that the loss of nucleosomal organization of the nuclear DNA is somehow related to the replacement of histones by DVNP as the main basic nuclear protein [75]. Interestingly, sequences with high similarity to DVNP were also found among ESTs of different dinoflagellates, including O. marina. On this information, we searched exhaustively our data and found 25 clusters with high similarity to DVNP (Tables 2 and 3). Of these, we analysed the amino acid translations of the 20 sequences that encompassed the complete protein (Figure 4). The proteins ranged between 134 and 142 amino acids in length and had a mean isoelectric point of 12.73, indicating a strong basic character. The predicted mean molecular weight was $14.8 \mathrm{KDa}$. The proteins exhibit secondary structure features similar to those found by Gornik et al. [75] in the Hematodinium DVNP: an alpha helix of variable length encompassing the first half of the protein followed by a 'helix-turn-helix' region (Figure 4). The O. marina DVNP sequences are predicted to have nuclear localization signals (NLS), a feature also found in the Hematodinium proteins [75].

As DVNP appear to be well established in O. marina, they must have taken their present role prior to the split between $O$. marina and the core dinoflagellates, but after the split of P. marinus [75]. Very likely, DVNP is the true identity of $\mathrm{Np23}$, the major basic nuclear protein detected previously in nuclear extracts of $O$. marina cells [79]. Notwithstanding, the presence of histone deacetylase genes suggests that histones and other associated factors are still functional in dinoflagellates, therefore it cannot be ruled out that at least part of the genome is arranged with the canonical nucleosomal organisation. Clearly more comprehensive genomic sequencing and molecular biology experiments must be done in order to determine what other conserved elements of chromatin and epigenetic regulation are involved in these protists.

\section{Transcription and RNA processing}

While the amount of dinoflagellate sequence data is increasing, the components of gene regulation in the group have largely been left unexplored, despite the recent claims that much of the regulation of dinoflagellate genes is controlled at the post-transcriptional level $[67,68,80,81]$. However, documenting the presence of 


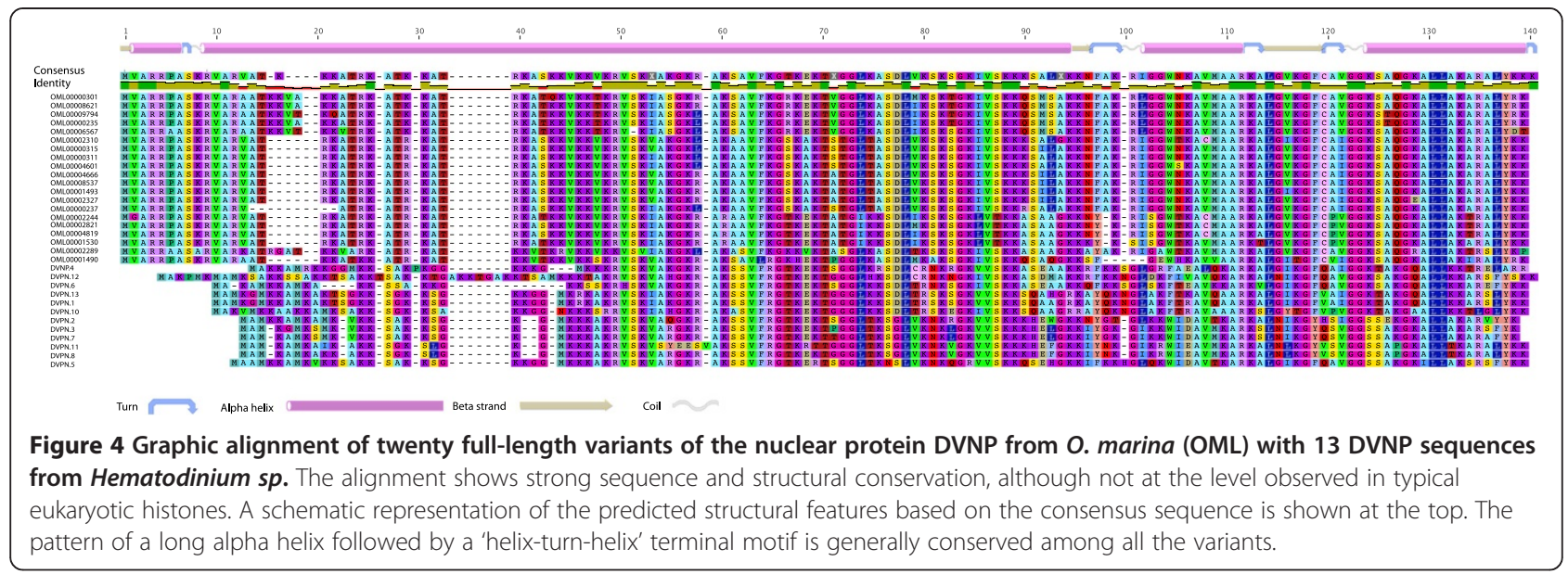

the canonical (or better-studied) regulatory pathways is also needed to determine the complexity of gene regulation. For instance, mRNA splicing and transcription are two broad categories that may be valuable to dissect in dinoflagellates. Splicing is of particular interest because there is extremely little information of introns and their features in the group, despite its large genome sizes. Further, the idea that all dinoflagellate mRNAs are trans-spliced with a leader sequence $[46,54]$ adds an additional layer of complexity to splicing and gene regulation.

We searched the O. marina clusters for the major mRNA splicing and transcription components using a consolidated list of 256 splicing proteins and 228 transcription proteins. A component was considered present if the $O$. marina cluster also wasn't identified via blasting from a different conserved splicing or transcriptional component. Additional file 1: Table S4 lists the genes involved in splicing or transcription with matches in our $O$. marina dataset, and their functions. In addition, potential genes of interest in this category contain Pfam domains for RNA recognition and/or binding and various types of DNA-binding domains such as zinc fingers and knuckles (Additional file 3: Figure S2). From the subset of splicing genes identified, the majority of them are either associated with the U6 or U2 snRNPs - the spliceosome parts that recognize the intron in the initial steps on splicing [82]. These include the Sm and Sm-like (Lsm) proteins. Curiously, the U6 snRNP is also the major spliceosome component that is known to participate in leader trans-splicing [83], so over-representation of U6 snRNP components may suggest elevated expression due to involvement in trans-splicing. Prp46 and Cwc2, also identified, are members of the Nineteen Complex (NTC) that acts in the first major step of splicing. Not identified in this EST survey includes the most conserved splicing protein (Prp8), although its particular constituent domains were (data not shown). Length limitations of the ESTs may also have prohibited the clear identification of the major transcription factors and the RNA polymerases involved in transcription - only auxiliary transcriptional components were identified, with many of those participating in processes unrelated to mRNA transcription.

\section{Retroelements}

Evidence for active retroelements that could provide reverse transcriptase (RT) activity could help us understand some of the unusual characteristics of dinoflagellate genomes $[84,85]$. In particular, endogenous RT would be necessary for a hypothesis that dinoflagellate mRNAs are frequently retrotranscribed into dsDNA and integrated into the genome [84]. This process would result in the creation of large numbers of retrogenes that accumulate in the genome, and may partially explain the large numbers of highly expressed genes. This model is supported by the presence of 'relic' spliced leaders (rSL) immediately after the SL sequence that caps every mRNA at the $5^{\prime}$ end. The rSL appear in a sizeable fraction of mRNAs from several species $[60,84]$ and are thought to be remnants of previous events of processing and recycling. The most common sources of endogenous RT activity in eukaryotic cells are LTR and non-LTR retrotransposons and telomerases, therefore we searched our EST data for sequences with similarity to known RT proteins but also to other features found in LTR and non-LTR transposons. Table 4 shows 14 clusters that were found to have similarity ( $\mathrm{E}$ value $<1.10^{-10}$ ) to retrotransposons, all matching different regions of LTR-transposons belonging to a single class, known as Ty1/copia. In addition, clusters unidentifiable by Blastx but containing Pfam domains related to TN functions are listed in the Additional file 1: Table S1. Ty1/copia is one of the two main types of LTR-retrotransposons, is ubiquitous in eukaryotes and has been most widely studied in plan genomes. LTR-transposons are capable of mobilization via a 'copy-and-paste' mechanism involving transcription of the element and making DNA copies by an RT protein 
encoded by the transcript itself. The replicative activity of retrotransposons is hindered most of the time to avoid the deleterious effects of their proliferation. This is achieved epigenetically by methylation of certain regions of the LTR that otherwise act as promoters, but under certain conditions, transcription is unleashed allowing the elements to replicate and proliferate. Uncontrolled bursts of retrotransposon activity can result in occupying large proportions of genomes in short periods of time, events that and are thought to have played and a vital role in the organisation and evolution of eukaryotic genomes. Outside these episodic and apparently rare events of proliferation, transcripts of retrotransposons occur at very low levels, if at all. Since the level of expression of retrotransposons may be a strong predictor of active transposition, we wondered if the transcripts we found in our data are indication that transposition is ongoing in O. marina. Unfortunately, it is very difficult to make meaningful comparisons with expression data from other organisms in absolute terms because every transposon-genome system is different and there are no comparative analysis done. Instead, we can compare the expression of the O. marina elements (as revealed by the number of ESTs) relative to other genes. Ty1/copia clusters in O. marina are expressed at low to moderate levels ( 1 to 20 ESTs per cluster), but collectively they add up to 97 ESTs (Table 4). If the number of ESTs representing a gene in the sample even as a rough approximation of its relative level of expression, Ty1/copia element is among the top in transcript abundance (compare to Table 3) and it would be reasonable to speculate that RT proteins are present. This is an interesting possibility because it would lend support to the hypothesized role of mRNA recycling in dinoflagellate genome evolution by showing that retrotransposons can be a suitable source of RT activity $[84,85]$.

\section{Lateral gene transfer}

Lateral gene transfer (LGT) has already been reported from O. marina, including the acquisition of bacterial AroB [15] and proteorhodopsin genes at least two times independently [14]. Detection of LGT in eukaryotic sequence data is not always as clear-cut, however, since confounding factors like sequence divergence, incomplete taxon sampling and a convoluted evolutionary history, or the presence of contaminating bacteria in the culture can complicate the interpretation of the phylogenies of suspected LGT cases. When we looked for potential LGT cases in our data we encountered combinations of all these factors, in particular the presence of about 600 bacterial sequences, presumably originating from contaminant DNA. While most of these sequences can be readily identified as contaminants, they undermine the level of certainty of potential LGT. In spite of this we have identified two additional genes with a conflicting phylogenetic signal suggesting horizontal acquisition from bacteria. Both cases share an intriguing pattern of being closely associated to an unrelated eukaryote but beyond that, embedded among bacteria (similar to a growing number of other cases of LGT, see [86]). Additional file 4: Figure S3 shows a phylogenetic analysis of the deduced protein sequence of cluster OML00001921 along with 2 sequences from diatoms, one from the ichthyosporean Sphaeroforma arctica and 46 eubacterial sequences of L-lactate permease (LctP). The O. marina sequence forms a strongly supported node with the other three eukaryotic sequences ( $100 \%$ bootstrap), which in turn is connected to various proteobacteria, mainly involving the subgroups gamma

Table 4 O. marina EST clusters with top Blastx hits corresponding to known transposable elements

\begin{tabular}{|c|c|c|c|c|}
\hline Cluster ID & Top hit Acc. & Top hit & E-value & ESTs \\
\hline OML00000073 & XP_002422173 & Hypothetical protein FOXB_16913 Fusarium oxysporum & $8.00 \mathrm{E}-27$ & 7 \\
\hline OML00000330 & ABA95820 & Hypothetical protein FOXB_16913 Fusarium oxysporum & $3.00 \mathrm{E}-38$ & 20 \\
\hline OML00002280 & ACB59199 & Copia-like protein [Brassica oleracea] & $7.00 \mathrm{E}-15$ & 3 \\
\hline OML00002762 & EFY94000 & Retrotransposon like protein [Metarhizium anisopliae ARSEF 23] & $8.00 \mathrm{E}-12$ & 3 \\
\hline OML00002917 & ABF93649 & Retrotransposon protein Ty1-copia subclass [Oryza sativa Japonica group] & $5.00 \mathrm{E}-18$ & 9 \\
\hline OML00002925 & CAB46043 & Retrotransposon like protein [Arabidopsis thaliana] & 4.00E-16 & 5 \\
\hline OML00004005 & BAB01972 & Copia-like retrotransposable element [Arabidopsis thaliana] & $2.00 \mathrm{E}-10$ & 12 \\
\hline OML00004886 & AAD32898 & Putative retroelement pol polyprotein [Arabidopsis thaliana] & $1.00 \mathrm{E}-16$ & 1 \\
\hline OML00005041 & AAP46257 & Putative polyprotein [Oryza sativa Japonica Group] & $8.00 \mathrm{E}-15$ & 4 \\
\hline OML00006583 & BAB01972 & Copia-like retrotransposable element [Arabidopsis thaliana] & $6.00 \mathrm{E}-12$ & 8 \\
\hline OML00009617 & XP_003376336 & Retrovirus-related Pol polyprotein from transposon TNT 1-94 [Trichinella spiralis] & $2.00 \mathrm{E}-13$ & 11 \\
\hline OML00010486 & EGU73258 & Hypothetical protein FOXB_16913 Fusarium oxysporum & $2.00 \mathrm{E}-21$ & 6 \\
\hline OML00010490 & BAB01972 & Copia-like retrotransposable element [Arabidopsis thaliana] & $3.00 \mathrm{E}-12$ & 5 \\
\hline OML00010499 & ABA95820 & Retrotransposon protein, putative, unclassified [Oryza sativa Japonica Group] & $1.00 \mathrm{E}-21$ & 3 \\
\hline Total & & & & 97 \\
\hline
\end{tabular}


and delta. The LctP protein catalyses the transport of L-lactate across membranes. It has been suited functionally only in a few species of bacteria, most notably in $E$. coli, where this gene is part of an operon involved in L-lactate utilisation [87]. In eukaryotes, members of the monocarboxylate transporter family (MCT) catalyze the proton-linked transport of monocarboxylates such as L-lactate, pyruvate, and the ketone bodies across the plasma membrane. Since LctP does not seem to have any relationship with the MCT family, and no other eukaryotic organisms were found to contain LctP-related sequences, an ancient, common origin of the four eukaryotic sequences shown in Additional file 4: Figure S3 is unlikely. At the same time, the fact that the eukaryotic sequences branch together to the exclusion of everything else makes it intriguing. If the lctP genes were acquired independently by $O$. marina, the diatoms and the ichthyosporean $S$. arctica, they have been transferred from the same or very similar donors. Alternatively, the gene may have been transferred from bacteria to one eukaryotic lineage, and then transferred between eukaryotes [86]. The second case is shown in Figure 5. Several clusters were found to be highly similar to alcohol dehydrogenase proteins (ADH) that seem to be absent from other eukaryotes except for one species, Euglena gracilis. Alcohol dehydrogenases belong in a very large superfamily of ancient origin known as MDR (medium-chain dehydrogenase/reductase) and is formed by zinc-dependent ADHs, quinone reductases, and many more families and subfamilies [88]. The most recent comprehensive study of MDR sequences identified over 500 families that can be ascribed to MDR superfamily, 8 of which are highly widespread with ADH being the largest [88]. In addition, the study recognized other 9 families of restricted scope but of special interest for their functions or potential relevance. The ADH sequences from $O$. marina are most similar to one family from this group of additional "special interest" MDR families tentatively named BurkDH family because of its prevalence among Burkholderia species and several other genera of proteobacteria including Pseudomonas, Brucella, Ralstonia and Rhizobium (Figure 5). Surprisingly, only one eukaryotic protein sequence can be found in Genbank that belongs in this family but it is from E. gracilis, a phototrophic freshwater protist completely unrelated

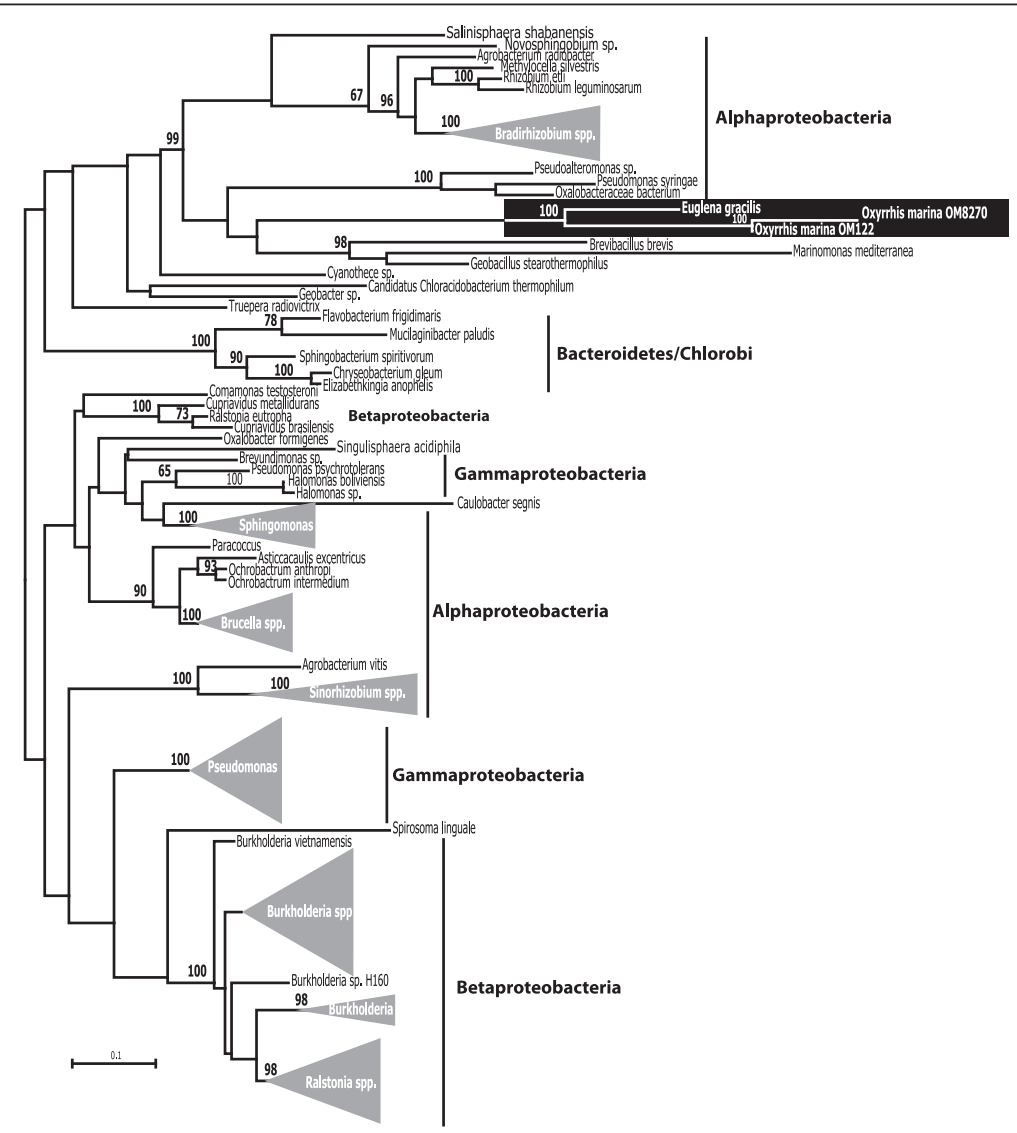

Figure 5 Schematic phylogenetic tree of amino acid sequences of Zinc-dependent Alcohol dehydrogenase proteins including representatives from the main bacterial lineages and $E$. gracilis and $O$. marina (highlighted in a black box), which are the only eukaryotic organisms for which homologs have been detected. The numbers at the nodes indicate bootstrap support when higher than $50 \%$. 
to O. marina. Unfortunately we are unable to make inferences as to the adaptive roles of this acquisition by $O$. marina and $E$. gracilis as no complete genome data are available for neither organism, therefore we do not know if other MDR paralogs are present. In addition, the function of BurkDH proteins has not yet been investigated [88]. These two cases illustrate puzzling scenarios that result of great interest for understanding the evolutionary dynamics of metabolic adaptation but are in turn difficult to interpret in the context of the current data. Clearly these cases will have to be reanalyzed when more, comprehensive from free-living protists (in these cases, dinoflagellates, euglenids, haptophytes) are available.

\section{Conclusions}

Our EST dataset from O. marina has so far yielded interesting insights into the evolution, genetics, phylogeny and metabolism of this species and dinoflagellates at large. Here we tapped on this valuable dataset to conduct additional investigations, this time concentrating on genes and molecular characteristics associated to nuclear and genomic biology, which is an area where dinoflagellates are particularly unusual. We describe several gene categories and show that $O$. marina contains many of the typically widespread components that comprise DNA repair, and gene expression, suggesting that in spite of the seemingly highly divergent nature of dinoflagellate nuclear processes, they still maintain many of the core eukaryotic mechanisms. Moreover, we find extensive gene redundancy and multiplicity, indicating transcription from multiple genomic loci. For some of the most highly represented transcripts, we estimate multiple genomic copies suggesting a positive correlation between transcript abundance and genomic copy number, which may be a generalized dinoflagellate feature. Extending on previous findings, we described two striking examples of lateral gene transfer, reinforcing the idea that acquisition of foreign genes plays an important role, in shaping the O. marina genome and further supporting the role of this phenomenon in adaptation on eukaryotes, particularly heterotrophic protists.

\section{Additional files}

Additional file 1: Table S1. PFAM domains found among the O. marina EST clusters with no hits to known proteins. Table S2- Primer sequences, melting temperature $\operatorname{Tm}\left({ }^{\circ} \mathrm{C}\right)$, and insert length (bp) for four O. marina genes. Table S3 (next page): O. marina encodes DNA repair and recombination proteins conserved in other eukaryotes. Homologs of components of the machinery for base excision repair (BER), mismatch repair (MMR), nucleotide excision repair (NER), homologous recombination (HR), meiosis-specific homologous recombination (HR-M1), DNA polymerase subunits involved in repair (DNAP), editing and processing nucleases (EPN), post-replication repair (PRR), chromatin structure relevant to repair (CS), the DNA damage checkpoint (DDC), DNA replication licencing (DRL), and DNA damage response (DDR) are present in O. marina. Data identified in the complete genome sequences of humans (H. sapiens), yeast (S. cerevisiae), kinetoplastids (T. brucei), parabasalids (T. vaginalis), apicomplexans ( $T$. gondii, C. parvum, and genome sequence survey of $A$. taiwanensis), and a dinoflagellate ( $P$. marinus) is compared with the $O$. marina ESTs. Table S4: The O. marina EST dataset contains a number of sequences with hits to proteins involved in transcriptional regulation and splicing. Listed below are eciprocal hits with a database built with curated proteins from $H$. sapiens and S. cerevisiae.

Additional file 2: Figure S1. O. marina encodes orthologs of meiosis-specific recombination genes. Aligned amino acid sites were analyzed by PhyML with an invarying and $8 \gamma$-distributed substitution rate categories and the LG substitution model. Numbers at the nodes indicate \% bootstrap support $(\geq 50 \%)$ from 1000 replicates. O. marina Spo 11 is closely related to apicomplexan Spo11-2. 218 sites, $\mathrm{LnL}=-10981.3$.

Additional file 3: Figure S2. O. marina encodes orthologs of meiosis-specific recombination genes. Aligned amino acid sites were analyzed by PhyML with an invarying and $8 \gamma$-distributed substitution rate categories and the LG substitution model. Numbers at the nodes indicate $\%$ bootstrap support $(\geq 50 \%)$ from 1000 replicates. O. marina Hop2 is most closely related to its ortholog in Perkinsus marinus, within the alveolates. 172 sites, $\mathrm{LnL}=-6417.0$.

Additional file 4: Figure S3. Phylogeny of representative L-lactate permease LctP proteins indicates that $O$. marina IctP is most closely related to ICtP in diatoms and an icthyosporean (S. arctica), which are derived from a clade of marine bacterial ICtP homologs. 502 amino acid sites were analyzed by PhyML with an invarying and $8 \gamma$-distributed substitution rate categories and the LG substitution model. Numbers at the nodes indicate \% support $(\geq 50 \%)$ from 1000 bootstrap replicates. $\mathrm{LnL}=-$ 23076.2. No other eukaryotic homologs were identified by BLASTp searches of the JGl, Broad Institute, or NCBI non-redundant databases, nor by tBLASTn searches of dbEST-others, with an e-value cutoff of 1. Some of the highly similar Neisseria and Haemophilus orthologous protein sequences were excluded from the phylogeny shown here.

\section{Competing interests}

The authors declare that they have no competing interests.

\section{Authors' contributions}

RL analysed data and drafted the paper, SBM conducted analysis of meiosis genes and lateral gene transfer and drafted sections of the paper, $\mathrm{HL}$ conducted real-time PCR experiments, JFS contributed to the data generation and analyses, PJK provided the cultures and data generation and drafted the paper, CHS conducted analyses, provided supervision and wrote the paper. All authors read and approved the final manuscript.

\section{Acknowledgements}

We thank Susana Breglia for the scanning electron micrographs depicted in Figure 3. C.H.S. and P.J.K are Fellows of the Canadian Institute for Advanced Research, Program on Integrated Microbial Biodiversity. S-B.M was supported by a CIFAR Global Academy fellowship. EST sequencing was done through the Protist EST Project (PEP) funded by Genome Canada and Genome Atlantic. P.J.K Is supported by NSERC (Discovery grant 227301); C.H.S. is supported by NSERC (Discovery Grant 386345-2010).

\section{Author details}

${ }^{1}$ Canadian Institute for Advanced Research, Program in Integrated Microbial Biodiversity, Alberta, Canada. ${ }^{2}$ Department of Biochemistry and Molecular Biology, Dalhousie University, B3H4R2 Halifax, NS, Canada. ${ }^{3}$ Botany Department, University of British Columbia, V6T1Z4 Vancouver, BS, Canada.

Received: 19 May 2013 Accepted: 6 February 2014 Published: 11 February 2014

\section{References}

1. Montagnes DJS, Lowe CD, Roberts EC, Breckels MN, Boakes DE, Davidson K, Keeling PJ, Slamovits CH, Steinke M, Yang Z, et al: An introduction to the special issue: oxyrrhis marina, a model organism? J Plankton Res 2011, 33(4):549-554

2. Saldarriaga JF, McEwan ML, Fast NM, Taylor FJ, Keeling PJ: Multiple protein phylogenies show that Oxyrrhis marina and Perkinsus marinus are early 
branches of the dinoflagellate lineage. Int J Syst Evol Microbiol 2003, 53(Pt 1):355-365.

3. Slamovits $\mathrm{CH}$, Saldarriaga JF, Larocque A, Keeling PJ: The highly reduced and fragmented mitochondrial genome of the early-branching dinoflagellate Oxyrrhis marina shares characteristics with both apicomplexan and dinoflagellate mitochondrial genomes. J Mol Biol 2007, 372(2):356-368.

4. Adl SM, Simpson AG, Lane CE, Lukes J, Bass D, Bowser SS, Brown MW, Burki F, Dunthorn M, Hampl V, et al: The revised classification of eukaryotes. J Euk Micro 2012, 59(5):429-493.

5. Lowe CD, Keeling PJ, Martin LE, Slamovits CH, Watts PC, Montagnes DJS: Who is Oxyrrhis marina? Morphological and phylogenetic studies on an unusual dinoflagellate. J Plankton Res 2011, 33(4):555-567.

6. Moreno Diaz de la Espina S, Alverca E, Cuadrado A, Franca S: Organization of the genome and gene expression in a nuclear environment lacking histones and nucleosomes: the amazing dinoflagellates. Eur $J$ Cell Biol 2005, 84(2-3):137-149.

7. Rizzo PJ: Biochemistry of the dinoflagellate nucleus. In The biology of dinoflagellates. Blackwell Botanical Monographs, Blackwell Publishing, Oxford, UK: Taylor FJR (Ed.); 1987:143-173.

8. Rizzo PJ: The enigma of the dinoflagellate chromosomes. J Protozool 1991, 38:246-252.

9. Rizzo PJ: Those amazing dinoflagellate chromosomes. Cell Res 2003, 13(4):215-217.

10. Spector DL: Dinoflagellate nuclei. In Dinoflagellates. Edited by Spector DL. New York: Academic Press; 1984:107-147.

11. Droop MR: Nutritional investigations of phagotrophic protozoa under axenic conditions. Helgolander Wiss Meeresunters 1970, 20:272-277.

12. Lowe $C D$, Martin $L E$, Watts $P C$, et al: Isolation and culturing strategies for the maintenance of Oxyrrhis marina. J Plankton Res 2011, 33(4):569-578.

13. Slamovits $\mathrm{CH}$, Keeling PJ: Plastid-derived genes in the nonphotosynthetic alveolate Oxyrrhis marina. Mol Biol Evol 2008, 25(7):1297-1306.

14. Slamovits CH, Okamoto N, Burri L, James ER, Keeling PJ: A bacterial proteorhodopsin proton pump in marine eukaryotes. Nat Commun 2011, 2:183.

15. Waller RF, Slamovits $\mathrm{CH}$, Keeling PJ: Lateral gene transfer of a multigene region from cyanobacteria to dinoflagellates resulting in a novel plastid-targeted fusion protein. Mol Biol Evol 2006, 23(7):1437-1443.

16. Fernandez-Robledo JA, Schott EJ, Vasta GR: Perkinsus marinus superoxide dismutase 2 (PmSOD2) localizes to single-membrane subcellular compartments. Biochem Biophys Res Commun 2008, 375(2):215-219.

17. Janouskovec J, Horak A, Obornik M, Lukes J, Keeling PJ: A common red algal origin of the apicomplexan, dinoflagellate, and heterokont plastids. Proc Natl Acad Sci U S A 2010, 107(24):10949-10954.

18. Sanchez-Puerta MV, Lippmeier JC, Apt KE, Delwiche CF: Plastid genes in a non-photosynthetic dinoflagellate. Protist 2007, 158(1):105-117.

19. Nash EA, Nisbet RE, Barbrook AC, Howe CJ: Dinoflagellates: a mitochondrial genome all at sea. Trends Genet 2008, 24(7):328-335.

20. Waller RF, Jackson CJ: Dinoflagellate mitochondrial genomes: stretching the rules of molecular biology. Bioessays 2009, 31(2):237-245.

21. Lowe CD, Mello LV, Samatar N, Martin LE, Montagnes DJ, Watts PC: The transcriptome of the novel dinoflagellate Oxyrrhis marina (Alveolata: Dinophyceae): response to salinity examined by 454 sequencing. BMC Genomics 2011, 12:519.

22. O'Brien EA, Koski LB, Zhang Y, Yang L, Wang E, Gray MW, Burger G, Lang BF: TBestDB: a taxonomically broad database of expressed sequence tags (ESTs). Nucleic Acids Res 2007, 35(Database issue):D445-D451.

23. Ewing B, Green P: Base-calling of automated sequencer traces using phred: II: error probabilities. Genome Res 1998, 8(3):186-194.

24. Gotz S, Garcia-Gomez JM, Terol J, Williams TD, Nagaraj SH, Nueda MJ, Robles M, Talon M, Dopazo J, Conesa A: High-throughput functional annotation and data mining with the Blast2GO suite. Nucleic Acids Res 2008, 36(10):3420-3435.

25. Wood RD, Mitchell M, Lindahl T: Human DNA repair genes, 2005. Mutat Res 2005, 577(1-2):275-283.

26. Wood RD, Mitchell M, Sgouros J, Lindahl T: Human DNA repair genes. Science 2001, 291(5507):1284-1289.

27. Berriman M, Ghedin E, Hertz-Fowler C, Blandin G, Renauld H, Bartholomeu DC, Lennard NJ, Caler E, Hamlin NE, Haas B, et al: The genome of the African trypanosome Trypanosoma brucei. Science 2005, 309(5733):416-422.

28. El-Sayed NM, Myler PJ, Blandin G, Berriman M, Crabtree J, Aggarwal G, Caler E, Renauld $\mathrm{H}$, Worthey EA, Hertz-Fowler $\mathrm{C}$, et al: Comparative genomics of trypanosomatid parasitic protozoa. Science 2005, 309(5733):404-409.
29. Carlton JM, Hirt RP, Silva JC, Delcher AL, Schatz M, Zhao Q, Wortman JR, Bidwell SL, Alsmark UC, Besteiro S, et al: Draft genome sequence of the sexually transmitted pathogen Trichomonas vaginalis. Science 2007, 315(5809):207-212.

30. Malik SB, Pightling AW, Stefaniak LM, Schurko AM, Logsdon JM Jr: An expanded inventory of conserved meiotic genes provides evidence for sex in Trichomonas vaginalis. PLoS One 2008, 3(8):e2879.

31. Blanton HL, Radford SJ, MCMahan S, Kearney HM, Ibrahim JG, Sekelsky J: REC, Drosophila MCM8, drives formation of meiotic crossovers. PLoS Genet 2005, 1(3):e40.

32. Cobbe N, Heck MM: The evolution of SMC proteins: phylogenetic analysis and structural implications. Mol Biol Evol 2004, 21(2):332-347.

33. Melo J, Toczyski D: A unified view of the DNA-damage checkpoint. Curr Opin Cell Biol 2002, 14(2):237-245.

34. Templeton TJ, Enomoto S, Chen WJ, Huang CG, Lancto CA, Abrahamsen MS, Zhu G: A genome-sequence survey for Ascogregarina taiwanensis supports evolutionary affiliation but metabolic diversity between a Gregarine and Cryptosporidium. Mol Biol Evol 2010, 27(2):235-248.

35. Guindon S, Dufayard JF, Lefort V, Anisimova M, Hordijk W, Gascuel O: New algorithms and methods to estimate maximum-likelihood phylogenies: assessing the performance of PhyML 3.0. Syst Biol 2010, 59(3):307-321.

36. Katoh K, Toh H: Parallelization of the MAFFT multiple sequence alignment program. Bioinformatics 2010, 26(15):1899-1900.

37. Larionov A, Krause A, Miller W: A standard curve based method for relative real time PCR data processing. BMC Bioinformatics 2005, 6:62.

38. Baxevanis AD, Ouellette BF: Bioinformatics: A Practical Guide to the Analysis of Genes and Proteins. Hoboken, HJ. USA: John Wiley \& Sons, Inc; 2005.

39. Mangot JF, Debroas D, Domaizon I: Perkinsozoa, a well-known marine protozoan flagellate parasite group, newly identified in lacustrine systems: a review. Hydrobiologia 2011, 659(1):37-48.

40. Shoguchi E, Shinzato C, Kawashima T, Gyoja F, Mungpakdee S, Koyanagi R, Takeuchi T, Hisata K, Tanaka M, Fujiwara M, et al: Draft assembly of the Symbiodinium minutum nuclear genome reveals dinoflagellate gene structure. Curr Biol: CB 2013, 23(15):1399-1408.

41. Bodyl A, Stiller JW, Mackiewicz P: Chromalveolate plastids: direct descent or multiple endosymbioses? Trends Ecol Evol 2009, 24(3):119-121. author reply 121-112.

42. Burki F, Flegontov P, Obornik M, Cihlar J, Pain A, Lukes J, Keeling PJ: Re-evaluating the green versus red signal in eukaryotes with secondary plastid of red algal origin. Genome Biol Evol 2012, 4(6):626-635.

43. Keeling PJ: The endosymbiotic origin, diversification and fate of plastids. Philos Trans R Soc Lond B Biol Sci 2010, 365(1541):729-748.

44. Doolittle WF: You are what you eat: a gene transfer ratchet could account for bacterial genes in eukaryotic nuclear genomes. Trends Genet 1998, 14(8):307-311.

45. Toulza E, Shin MS, Blanc G, Audic S, Laabir M, Collos Y, Claverie JM, Grzebyk D: Gene expression in proliferating cells of the dinoflagellate Alexandrium catenella (Dinophyceae). Appl Environ Microbiol 2010, 76(13):4521-4529.

46. Lidie KB, Van Dolah FM: Spliced leader RNA-mediated trans-splicing in a dinoflagellate: Karenia brevis. J Euk Micro 2007, 54(5):427-435.

47. Bachvaroff TR, Place AR, Coats DW: Expressed sequence tags from Amoebophrya sp. infecting Karlodinium veneficum: comparing host and parasite sequences. J Euk Micro 2009, 56(6):531-541.

48. Yang I, John U, Beszteri S, Glockner G, Krock B, Goesmann A, Cembella AD: Comparative gene expression in toxic versus non-toxic strains of the marine dinoflagellate Alexandrium minutum. BMC Genomics 2010, 11:248.

49. Oh HM, Kang I, Vergin KL, Lee K, Giovannoni SJ, Cho JC: Genome sequence of Oceanicaulis sp. strain HTCC2633, isolated from the Western Sargasso Sea. J Bacteriol 2011, 193(1):317-318.

50. Strompl C, Hold GL, Lunsdorf H, Graham J, Gallacher S, Abraham WR, Moore ER, Timmis KN: Oceanicaulis alexandrii gen. nov., sp. nov., a novel stalked bacterium isolated from a culture of the dinoflagellate Alexandrium tamarense (Lebour) Balech. Int J Syst Evol Microbiol 2003, 53(Pt 6):1901-1906.

51. Alavi M, Miller T, Erlandson K, Schneider R, Belas R: Bacterial community associated with Pfiesteria-like dinoflagellate cultures. Environ Microbiol 2001, 3(6):380-396

52. Biegala IC, Kennaway G, Alverca E, Lennon JF, Vaulot D, Simon N: Identification of bacteria associated with dinoflagellates (Dinophyceae) Alexandrium spp. using tyramide signal amplification-fluorescent in situ hybridization and confocal microscopy. J Phycol 2002, 38(2):404-411. 
53. Jasti S, Sieracki ME, Poulton NJ, Giewat MW, Rooney-Varga JN: Phylogenetic diversity and specificity of bacteria closely associated with Alexandrium spp. and other phytoplankton. Appl Environ Microbiol 2005, 71(7):3483-3494.

54. Zhang H, Hou Y, Miranda L, Campbell DA, Sturm NR, Gaasterland T, Lin S: Spliced leader RNA trans-splicing in dinoflagellates. Proc Natl Acad Sci U S A 2007, 104(11):4618-4623.

55. Bertomeu T, Morse D: Isolation of a dinoflagellate mitotic cyclin by functional complementation in yeast. Biochem Biophys Res Commun 2004, 323(4):1172-1183.

56. Lee DH, Mittag M, Sczekan S, Morse D, Hastings JW: Molecular cloning and genomic organization of a gene for luciferin-binding protein from the dinoflagellate Gonyaulax polyedra. J Biol Chem 1993, 268(12):8842-8850.

57. Bachvaroff TR, Place AR: From stop to start: tandem gene arrangement, copy number and trans-splicing sites in the dinoflagellate Amphidinium carterae. PLoS One 2008, 3(8):e2929.

58. Sano J, Kato $\mathrm{KH}$ : Localization and copy number of the protein-coding genes actin, alpha-tubulin, and HSP90 in the nucleus of a primitive dinoflagellate. Oxyrrhis Marina Zoolog Sci 2009, 26(11):745-753.

59. Hou Y, Lin S: Distinct gene number-genome size relationships for eukaryotes and non-eukaryotes: gene content estimation for dinoflagellate genomes. PLoS One 2009, 4(9):e6978.

60. Jaeckisch N, Yang I, Wohlrab S, Glockner G, Kroymann J, Vogel H, Cembella A, John U: Comparative genomic and transcriptomic characterization of the toxigenic marine dinoflagellate alexandrium ostenfeldii. PLoS One 2011, 6(12):e28012.

61. Morey JS, Monroe EA, Kinney AL, Beal M, Johnson JG, Hitchcock GL, Van Dolah FM: Transcriptomic response of the red tide dinoflagellate, Karenia brevis, to nitrogen and phosphorus depletion and addition. BMC Genomics 2011, 12(1):346.

62. Moustafa A, Evans AN, Kulis DM, Hackett JD, Erdner DL, Anderson DM, Bhattacharya D: Transcriptome profiling of a toxic dinoflagellate reveals a gene-rich protist and a potential impact on gene expression due to bacterial presence. PloS One 2010, 5(3):e9688.

63. Ganley AR, Kobayashi T: Highly efficient concerted evolution in the ribosomal DNA repeats: total rDNA repeat variation revealed by whole-genome shotgun sequence data. Genome Res 2007, 17(2):184-191.

64. Robellet X, Flipphi M, Pegot S, Maccabe AP, Velot C: AcpA, a member of the GPR1/FUN34/YaaH membrane protein family, is essential for acetate permease activity in the hyphal fungus Aspergillus nidulans. Biochem J 2008, 412(3):485-493.

65. Gentsch M, Kuschel M, Schlegel S, Barth G: Mutations at different sites in members of the Gpr1/Fun34/YaaH protein family cause hypersensitivity to acetic acid in Saccharomyces cerevisiae as well as in Yarrowia lipolytica. FEMS Yeast Res 2007, 7(3):380-390

66. Duftner N, Larkins-Ford J, Legendre M, Hofmann HA: Efficacy of RNA amplification is dependent on sequence characteristics: implications for gene expression profiling using a cDNA microarray. Genomics 2008, 91(1):108-117.

67. Brunelle SA, Vand FM: Post-transcriptional regulation of S-phase genes in the dinoflagellate: Karenia brevis. J Euk Micro 2011, 58(4):373-382.

68. Erdner DL, Anderson DM: Global transcriptional profiling of the toxic dinoflagellate Alexandrium fundyense using massively parallel signature sequencing. BMC Genomics 2006, 7:88.

69. Machabee $S$, Wall L, Morse D: Expression and genomic organization of a dinoflagellate gene family. Plant Mol Biol 1994, 25(1):23-31.

70. Von Stosch HA: La signification cytologique de la cyclose nucleaire dans le cycle de vie des Dinoflagellates. Soc Bot Fr Memoires 1972:201-212.

71. Von Stosch HA: Observations on vegetative reproduction and sexual life cycles of two freswater dinoflagellates, Gymnodinium pseudopalustre Schiller and Woloszynkskia apiculata sp. Nov. Br Phycol J 1973, 8:105-134.

72. Montagnes DJ, Lowe CD, Martin L, Watts PC, Downes-Tettmar N, Yang Z, Roberts EC, Davidson K: Oxyrrhis marina growth, sex and reproduction. J Plankton Res 2011, 33(4):615-627.

73. Ramesh MA, Malik SB, Logsdon JM Jr: A phylogenomic inventory of meiotic genes; evidence for sex in Giardia and an early eukaryotic origin of meiosis. Curr Biol: CB 2005, 15(2):185-191.

74. Villeneuve AM, Hillers KJ: Whence meiosis? Cell 2001, 106(6):647-650.

75. Gornik SG, Ford KL, Mulhern TD, Bacic A, McFadden Gl, Waller RF: Loss of nucleosomal DNA condensation coincides with appearance of a novel nuclear protein in dinoflagellates. Curr Biol: CB 2012, 22(24):2303-2312.
76. Li JY: Studies on dinoflagellate chromosomal basic protein. Biosystems 1983, 16(3-4):217-225.

77. Roy S, Morse D: A full suite of histone and histone modifying genes are transcribed in the dinoflagellate Lingulodinium. PLoS One 2012, 7(4):e34340

78. Wong JT, New DC, Wong JC, Hung VK: Histone-like proteins of the dinoflagellate Crypthecodinium cohnii have homologies to bacterial DNA-binding proteins. Eukaryot Cell 2003, 2(3):646-650.

79. Kato KH, Moriyama A, Huitorel P, Cosson J, Cachon M, Sato H: Isolation of the major basic nuclear protein and its localization on chromosomes of the dinoflagellate: Oxyrrhis marina. Biol Cell 1997, 89(1):43-52.

80. Okamoto OK, Hastings JW: Genome-wide analysis of redox-regulated genes in a dinoflagellate. Gene 2003, 321:73-81.

81. Okamoto OK, Hastings JW: Novel dinoflagellate clock-related genes identified through microarray analysis. J Phycol 2003, 39:519-526.

82. Valadkhan S: Role of the snRNAs in spliceosomal active site. RNA Biol 2010, 7(3):345-353.

83. Blumenthal T: Trans-splicing and operons in C. elegans. The C. elegans Research Community, WormBook: WormBook, ed; 2012. doi/10.1895/wormbook.1.5.2, http://www.wormbook.org.

84. Slamovits $\mathrm{CH}$, Keeling PJ: Widespread recycling of processed CDNAs in dinoflagellates. Curr Biol: CB 2008, 18(13):R550-R552.

85. Slamovits $\mathrm{CH}$, Keeling PJ: Contributions of Oxyrrhis marina to molecular biology, genomics and organelle evolution of dinoflagellates. J Plankton Res 2011, 33(4):591-602.

86. Andersson JO, Roger AJ: Evolution of glutamate dehydrogenase genes: evidence for lateral gene transfer within and between prokaryotes and eukaryotes. BMC Evol Biol 2003, 3:14.

87. Dong JM, Taylor JS, Latour DJ, luchi S, Lin EC: Three overlapping Ict genes involved in L-lactate utilization by Escherichia coli. J Bacterio/ 1993, 175(20):6671-6678.

88. Persson B, Hedlund J, Jornvall H: Medium- and short-chain dehydrogenase/ reductase gene and protein families: the MDR superfamily. Cell Mol Life SCi 2008, 65(24):3879-3894.

doi:10.1186/1471-2164-15-122

Cite this article as: Lee et al:: Analysis of EST data of the marine protist Oxyrrhis marina, an emerging model for alveolate biology and evolution. BMC Genomics 2014 15:122.

\section{Submit your next manuscript to BioMed Central and take full advantage of:}

- Convenient online submission

- Thorough peer review

- No space constraints or color figure charges

- Immediate publication on acceptance

- Inclusion in PubMed, CAS, Scopus and Google Scholar

- Research which is freely available for redistribution 